\title{
GESTÃO ESCOLAR: UM ESTUDO DE CASO NA CONCEPÇÃO DOS DIRETORES
}

\author{
School Management: A case study in the design of directors
}

DOI: $10.30612 /$ re-ufgd.v6i11.8759

\author{
Karla Alexandra Benites Florenciano ${ }^{1}$ \\ Bianca Rodrigues Marcelino Alexandre ${ }^{2}$ \\ Maria Elena Aquino Dutra ${ }^{3}$
}

Recebido: 07/12/2018

Aceito: $29 / 05 / 2019$

\begin{abstract}
Resumo - o presente trabalho objetiva apresentar um estudo de caso realizado na disciplina de gestão escolar do $4^{\circ}$ semestre do curso de pedagogia da universidade federal do mato grosso do sul (ufms) diante das discussões em sala de aula, do qual foi solicitado pela professora que realizássemos uma entrevista com um diretor de uma escola pública ou privada para conhecer como é a função do gestor nestas escolas. As entrevistas foram realizadas com dois diretores de duas escolas públicas municipais, onde estes relataram sobre as dificuldades, as superações e os contrastes encontrados na gestão escolar, além de seus anseios diante das normas impostas e das resistências que enfrentam para administrar os problemas financeiros, pedagógicos e até pessoais que perpassam por toda a escola. A proposta inicial da entrevista é que ela fosse filmada do qual apenas o primeiro entrevistado permitiu que fosse feito desta maneira, já o segundo optou pela gravação da entrevista em áudio, permitindo que colocasse fotos da escola. Desta forma, aqui estão situadas as perguntas realizadas e as respostas dos entrevistados relacionado-as com teóricos que dão alusão a gestão democrática e suas características, promovendo uma análise e reflexão sobre o que é a gestão e como ela é vista hoje por aqueles que atuam nesta área da educação. A partir deste estudo, verificou-se que o gestor escolar exerce um papel de grande responsabilidade perante a comunidade escolar e que quando este trabalho é realizado com a participação efetiva de todos, a gestão democrática torna se possível.
\end{abstract}

Palavras - chave: Gestão democrática; Gestor; Escola.

Abstract - The present study aims to present a case study carried out in the School Management discipline of the 4th Semester of the Pedagogy Course of the Federal University of Mato Grosso do Sul (UFMS) in front of the classroom discussions, which the teacher asked us to carry out an interview with a director of a public or private school to learn about the role of the manager in these schools. The interviews were conducted with two directors of municipal public schools, where they reported on the difficulties, overruns and contrasts found in school management, in addition to their expectations of the imposed norms and the resistance they face in managing financial, pedagogical and even personal pervading throughout the school. The proposal of the interview is that it was filmed of which only the first interviewee allowed it to be done this way, the second one opted for

1 Universidade Federal da Grande Dourados karlinhaben@gmail.com

2 Universidade Federal de Mato Grosso do Sul biancarmalexandre@gmail.com

3 Universidade Federal de Mato Grosso do Sul mariaelena.aquino2@gmail.com

Florenciano et al, p. 93-106 
recording the audio interview, allowing him to put pictures of the school. Here are also the questions asked and the answers of the interviewees related to other articles and books that allude to democratic management and its characteristics, promoting an analysis and reflection on what is the management and how it is seen today by those who work in this area of education. It is noticed that the school manager plays a major role in the school community and that when this work is carried out with the effective participation of all, democratic management becomes more possible.

Keywords: Democratic management; Manager; School.

\section{Introdução}

A Universidade Federal de Mato Grosso do Sul localizada no município de Ponta Porã/MS dispõe-se de quatro cursos, um dos cursos ofertados na UFMS, é voltado para a área educacional sendo então Pedagogia.

Dentro do curso de Pedagogia possui uma disciplina de Gestão Escolar, que tem como objetivo conhecer os conceitos básicos de uma Gestão Escolar e qual a importância de uma gestão democrática e suas implicações na escolarização.

A gestão democrática está relacionada a uma coordenação pedagógica, que é composta por todos os participantes da escolarização, diretamente vinculados ou não a escola, na qual conta com a participação da comunidade escolar, professores, pais, direção e entre outros. A partir de uma gestão democrática é possível desempenhar funções conjuntas para o melhor desempenho da escola.

Conforme foi desenvolvido a pesquisa, ficou claro na fala dos gestores a importância de se envolver a comunidade em meio às responsabilidades escolares, para que entendam o funcionamento do processo de desenvolvimento de cada função, tendo como objetivo a democratização das decisões a fim de dar autonomia e buscar a identidade da escola.

Segundo Veiga (2005) uma das formas de dar liberdade a escola é formulando seu próprio Projeto Político Pedagógico (PPP), no qual é feito de forma conjunta, tendo como objetivo alcançar as propostas da escola, buscando a melhoria na qualidade educacional.

\section{Metodologia}

Essa pesquisa é um estudo de caso de cunho qualitativo, que tem como objetivo “descrever um fato existente" (TRIVIÑOS, 1987 p. 110) em que o pesquisador expressa uma problemática ao interagir com o ambiente a ser pesquisado, na qual interpreta os dados em meio há uma análise minuciosa. 
A devida pesquisa foi desenvolvida em cinco etapas: revisão bibliográfica; formulação da entrevista; definição dos diretores do município de Ponta Porã; desenvolvimento da coleta de dados e; análise dos dados obtidos.

A revisão bibliográfica sobre os dados obtidos e sua abrangência encontra-se na introdução deste artigo e o instrumento da coleta de dados utilizada na devida pesquisa foi à entrevista que, segundo Lakatos (2003), define como:

[...] o encontro entre duas pessoas, a fim de que uma delas obtenha informações a respeito de determinado assunto, mediante uma conversação de natureza profissional. É um procedimento utilizado na investigação social, para a coleta de dados ou para ajudar no diagnóstico ou no tratamento de um problema social (LAKATOS, 2003 p.195).

A conversação consistia em realizar onze perguntas aos diretores selecionados com o intuito de analisar o processo de gestão democrática a partir da fala dos diretores, as perguntas feitas foram: O que é Gestão Democrática a seu ver? Você considera a sua gestão democrática? Porque? Quais são os tipos de problemas que uma gestão enfrenta? E como a gestão da escola lida com eles? Quais são as maiores responsabilidades de uma gestão democrática? Quais os aspectos negativos do trabalho de um gestor? E quais os aspectos positivos? De quanto em quanto tempo é reformulado o PPP da sua escola? Como ele é construído? As verbas destinadas para a escola pelo governo são suficientes para sanar as necessidades da escola? O que você pensa sobre a escola de hoje, ela precisa mudar em algum aspecto ou está boa do jeito que está? Como você vê o papel do gestor hoje dentro da escola? Durante todo o seu período como gestora? Como você estimula a participação dos professores, funcionários, pais, alunos e comunidade na realização de atividades diversas na escola? (Luck, 2009, p.75); Sua escola possui conselho escolar? O plano de ensino da escola é feita anual ou bimestral?

Para a seleção dos diretores, a proposta era entrevistar um gestor da rede municipal e um gestor da rede estadual de educação, porém ao tentar contactar o gestor de escola estadual, uma das pesquisadoras não foi bem receptiva e, conforme a não aceitação da cooperação com a pesquisa, foi mudado para duas escolas municipais, no entanto mesmo conseguindo dois entrevistadores uma das entrevistas foi devidamente gravada apenas por áudio, por resistência do diretor

O processo de realização da pesquisa se deu no mês de novembro de 2017 com a duração delas foram em torno de 15 a 20 minutos. Os locais da entrevista foram diretamente na escola e, posteriormente foram transcritas e revisadas para serem fiéis as falas dos gestores que foram denotados como entrevistado 1 e entrevistado 2. 


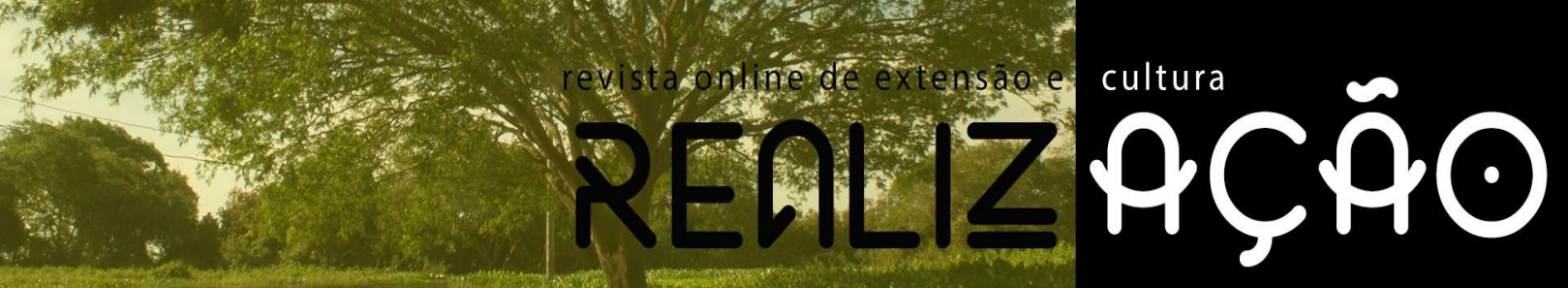

De acordo com as respostas os gestores entrevistados conhecem e acreditam que exercem uma gestão democrática nas escolas em que trabalham, que segundo Luck (2009) é aquela das quais seus participantes estão coletivamente organizados e compromissados com a promoção de qualidade para todos. Quando se referem à questão de participação eles citam que em seus locais de gestão se busca da melhor maneira possível se embasar e trabalhar coletivamente, realizando debates e discussões em busca de um entendimento de forma que venha a favorecer a toda a comunidade escolar.

Seguindo a discussão sobre gestão, podemos compreender melhor como ela se ocorre. Entrevistador: Que tipos de problemas uma gestão enfrenta? E como a gestão da escola lida com eles?

"Olha como eu sou diretora de escola pública, o maior problema é o servidor
público em si, que por muitas vezes não encaram a escola como uma
empresa. Tem assim uma dificuldade de cumprir regras, normas, horários,
entendeu? Esse pra mim é meu maior problema. Estar cobrando essa postura
do cumprimento das regras e normas, mas quando você faz assim, porque eu
sou diretora de escola pública a 12 anos e eu aprendi assim, que quando você
conquista as pessoas e faz entenderem que o trabalho delas que é importante.
Que se alguém fala do trabalho da limpeza, não tá falando do diretor e sim
do da pessoa responsável pela limpeza e então quando você conquista, você
consegue melhorar aí e as coisas e é nesse lado assim, que eu minimizei as
dificuldades de lidar com essas situações" [sic] (ENTREVISTADOR 1)

"Além dos problemas de relacionamento existem os financeiros, pedagógicos, porque pelo menos eu sou um diretor mais pedagógico do que administrativo, o Lucas ele é secretário da escola e me dá uma mão muito grande nesta parte é de administração. Porque assim, eu acabo me envolvendo mais com o pedagógico não sei se é por eu ter trabalhado muito tempo como coordenador e me sinto mais coordenador e me preocupo mais com o pedagógico, então, entre aprendizagem ou qualquer outra coisa o aluno vem em primeiro lugar. Então, é assim a preocupação de melhorar a parte pedagógica. Faz cinco anos que eu estou aqui nesta escola como coordenador a agora como diretor e o ano que vem sai o resultado do IDEB, e esse IDEB não é resultado de um ano, então quando eu entrei aqui a minha primeira turma do primeiro ano foi alfabetizada, participou do projeto junto comigo, e acompanhei aluno por aluno que hoje eles estão no quinto e fizeram essa avaliação da prova Brasil, e assim a nossa vontade é saí da penúltima colocação e chegar entre os três primeiros das escolas municipais. E isto foi feito um trabalho durante quatro e este cinco anos para tentar ano que vem tem um bom resultado, então assim, a parte pedagógica são coisas assim que a gente tá se preocupando o tempo todo, e parte financeira que a escola não tem verbas." [sic] (ENTREVISTADOR 2)

Uma das qualidades colocadas para aquele que vai gerir uma empresa como o espírito de liderança e a capacidade de saber administrar problemas é importante para que se possa 
gerir a empresa de forma democrática. Além de problemas econômicos e financeiros, encontra-se problemas relacionados ao fator humano, como a ocorrência de comportamentos e atitudes inadequados de funcionários e a dificuldade destes em obedecer regras e normas.

Os problemas encontrados na escola se assemelham aos de uma empresa, e o gestor deve possuir o discernimento e a capacidade para poder administrar problemas que possam surgir. Os gestores entrevistados, apesar das dificuldades encontradas como o caso do primeiro gestor entrevistado que coloca a dificuldade em lidar com aqueles que não querem cumprir as regras existentes na escola. Portanto ressaltam que umas das maiores dificuldades não é lidar com o financeiro, mas principalmente com o fator humano e com os adultos.

De acordo com Paro (2010, p. 766-767):

Considerada a escola como uma empresa, sua administração, ao cuidar da utilização racional ao cuidar dos recursos supõe que tal utilização seja realizada por uma multiplicidade de pessoas, mas sem ignorar que em cada um dos trabalhos (que concretizam essa realização) está presente o problema administrativo, ou seja, a necessidade de realizá-lo da forma mais adequada para a consecução do fim que se tem em mira.

Uma outra preocupação colocada pelo entrevistado 2 é a sua intenção em elevar a escola que está sobre sua gestão para um dos primeiros colocados no ranking do IDEB (Índice de Desenvolvimento da Educação Básica) no ano de 2017, do qual nos anos anteriores segundo dados do site do INEP (2017) no ano de 2015 a escola atingiu a sua meta que era de 4,8 onde atingiu 5,2, sendo a meta do gestor chegar na média 6,0 que é a média das escolas que estão nos primeiros lugares.

A escola que esta sobre a gestão do Entrevistado 1, segundo os dados do INEP (BRASIL, 2017) em 2015 tinha como meta 4,9, vindo a atingir a média 6,0 em comparação com a segunda escola está junto com as escolas que possuem a meta estabelecida pelo governo federal e está entre as primeiras colocadas.

O Índice de Desenvolvimento da Educação Básica (IDEB) foi criado no ano de 2007, onde reuni em um só indicador, dois conceitos que são o fluxo escolar e as médias de desempenho nas avaliações, calculado a partir de dados sobre aprovação escolar, obtidos no Censo Escolar, e nas médias de avaliações do Inep, o Sistema de Avaliação da Educação Básica (SAEB) e a Prova Brasil, que tem por intuito traçar metas de qualidade educacional para os sistemas, também considerado um condutor de política pública em prol da qualidade da educação. (BRASIL, 2017)

Quando o Entrevistado 2 especifica sua maior preocupação com o pedagógico, nota- 
se o seu interesse em colocar a sua escola em um patamar mais elevado em relação aos índices que sua escola apresenta em relação às outras do município, surgindo assim o que é proposto por Cury (2002, pág. 173) onde pontua que é a partir de uma gestão democrática que nascem os desafios, as perspectivas de uma democratização da escola brasileira, desconstruindo desigualdades, discriminações e posturas autoritárias, construindo um espaço de igualdade de oportunidade e tratamento igualitário de cidadãos entre si.

Entrevistador: Quais são as maiores responsabilidades de uma gestão democrática?

"É você ter conhecimento, se você não tem conhecimento e segurança do que você está fazendo, conhecimento profundo, você não consegue administrar, uma, uma, ser fazer uma gestão democrática porque? Porque quando você joga um problema para o grupo, você tem que ter o jogo de cintura pra fazer aquilo fechar. Porque se não se abre muito, porque as pessoas têm muita dificuldade, de entender que quando você trabalha em grupo, não é a tua opinião que tem que vencer, é a opinião do grupo, um pouco daqui, dali, dali, até que o grupo ficou esse. Então se você não tem essa segurança esse jogo de cintura esse conhecimento para administrar essa discussão, acaba que a coisa pode se perder, porque cada um quer que aconteça do jeito que a gente quer que seja. Então antes você tem que conquistar ele, fazer ele entender, fazer ele entender que a opinião que tem que sair dali é a do grupo, não é a minha, não é a dele, é a do grupo. É uma coisa que vai se moldando como se fosse uma colcha de retalho, até chegar para o que é melhor para o grupo e para a situação em questão" [sic] (ENTREVISTADOR 1)
“A parte pedagógica são coisas que a gente tem que ficar se preocupando o tempo todo e a parte financeira, onde recebemos muito pouco dinheiro que vem do PDDE. Nós recebemos um valor muito pequeno em relação ao $P D D E$ que é $R \$ 3.700,00$, que esse valor é para custeio e capital, tira $R \$$ 700,00 pra capital o restante é pra custeio, e esse valor eu tenho que manter a escola durante o ano todo, com material escolar, todo tipo de material escolar, principalmente caderno, lápis, borracha e apontador, porque temos que fornecer para nossos alunos, porque a grande maioria não tem todos os dias eu forneço caderno, lápis, borracha porque eles vem sem material, as famílias não tem como adquirir e esse dinheiro também tem que investir na parte de limpeza, tanto em produtos para limpar o piso e pra a louça, então todo o material de limpeza também é gasto com esse valor, e esse valor é semestralmente, com uma parcela no início do ano e outra que cai no final do ano mas só em Dezembro, então praticamente uso o valor de $R \$$ $3.700,00$ no ano, porque a próxima parcela que vou receber de agora vai ser só em 31 de Dezembro, que eu vou poder usar ano que vem. Então, assim é através de promoção pra eu conseguir manter. A nossa escola o diferencial dela é: localizada num lugar muito carente que precisa de uma assistência social é diferente por exemplo, até mesmo da escola X, que está num patamar melhor, como ali a saída é com carros é diferente daqui que as crianças a maioria vem todas a pé e a situação socioeconômica a gente $j a ́$ ve, e isso interfere diretamente dentro de uma escola, tanto na parte de aprendizagem, na parte de comportamento, é tudo. [sic] (ENTREVISTADO 


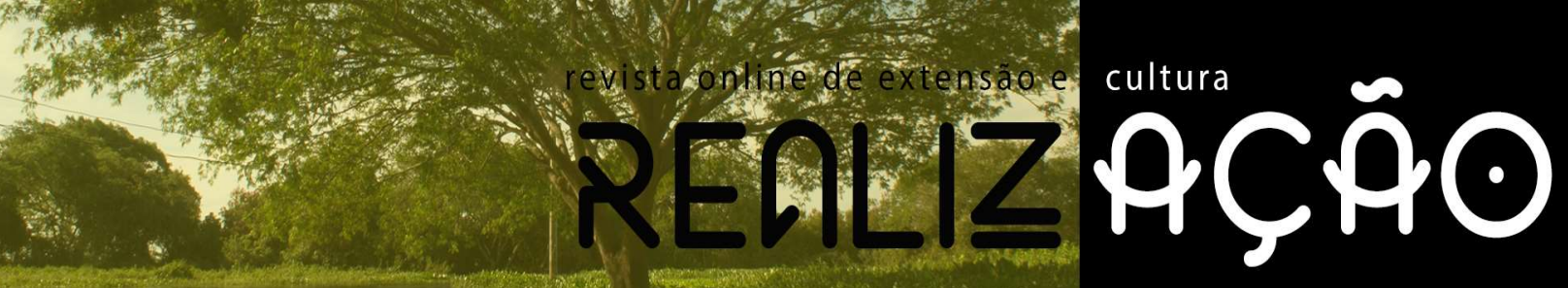

2)

Ao analisar as respostas dos dois gestores é notado que as respostas de ambos se assemelham ao fato da dificuldade em se lidar com as atitudes humanas no ambiente escolar, mas o segundo entrevistado relata também sobre um problema existente em seu local de trabalho que é a questão financeira, que toda a gestão encontra, mas que em seu local de gestão é muito grande, pelo fato da escola receber uma verba muito pequena para sanar todos os gastos da escola, assim como uma característica que diferencia sua escola da outra que é a condição socioeconômica dos alunos e de seus pais que afetam toda a sua administração.

De acordo com Brasil (2017) o Programa Dinheiro Direto na Escola (PDDE) é uma assistência financeira às escolas públicas da educação básica, das escolas estaduais, municipais e do Distrito Federal e às escolas privadas de educação especial mantidas por entidades sem fins lucrativos, com intuito de melhorar a estrutura física e pedagógica, o reforço da autogestão escolar e a elevação dos índices de desempenho da educação básica. O recurso é transferido de acordo com o número de alunos, de acordo com o censo escolar, anterior ao repasse.

Entrevistador: Quais são os aspectos negativos do trabalho de um gestor? E quais os aspectos positivos?

\begin{abstract}
"Na minha opinião o positivo, é que o gestor ele tem é amplo, pelo menos eu né? Sempre tive ampla autonomia de fazer acontecer coisas que na educação se você não, não tá a frente de uma administração você não consegue fazer, você depende de outro pra você lançar suas ideias, na minha opinião é essa. Que as outras escolas que eu fui gestora, eu consegui fazer coisas assim, pela educação, fantásticas. Porque? Coisas que eu acredito que seja melhor para o aluno aprender, pru ensino aprendizagem e muitos não acreditam, eu ia conquistando os professores, por exemplo para projeto de festival de teatro por exemplo, trabalhando desde a leitura, o significado das coisas e tal. Então aí você consegue fazer isso. Se você não é o gestor, você é o coordenador assim como eu sou concursada, você depende da gente. Se a diretora não for com a tua ideia, simplesmente ela vai te cortar e pronto. Então uma das coisas que eu acho fantástico ser professor, é essa mesma. É essa questão de você poder colocar em ação, coisas que faz a educação fruir, né?1 E que você dependa da secretaria de educação, mas como a secretária que as coisas aconteçam a gente tem essa autonomia. E o ponto negativo que eu acho é justamente, o que eu tinha dito anteriormente, esse controle que a gente tem que ter de horário, de cumprir as regras, as normas, que as pessoas infelizmente tem muita dificuldade de relação a isso, aqui no Mato Grosso do SUL. Lá no meu estado que é o Nordeste as pessoas são mais assim, acho que são mais cobradas então as pessoas têm na cabeça de ser diferente nessa questão de normas e regras né?1 Eu sou de lá vim de lá, não é?! Aqui não, aqui as pessoas, pelo menos a escola, tem uma coisa assim que eu acho esquisita, eles não consideram a escola como uma empresa, sabe assim?! Tipo vamos fazer assim, não assado. Tem currículo, tem uma metodologia
\end{abstract}




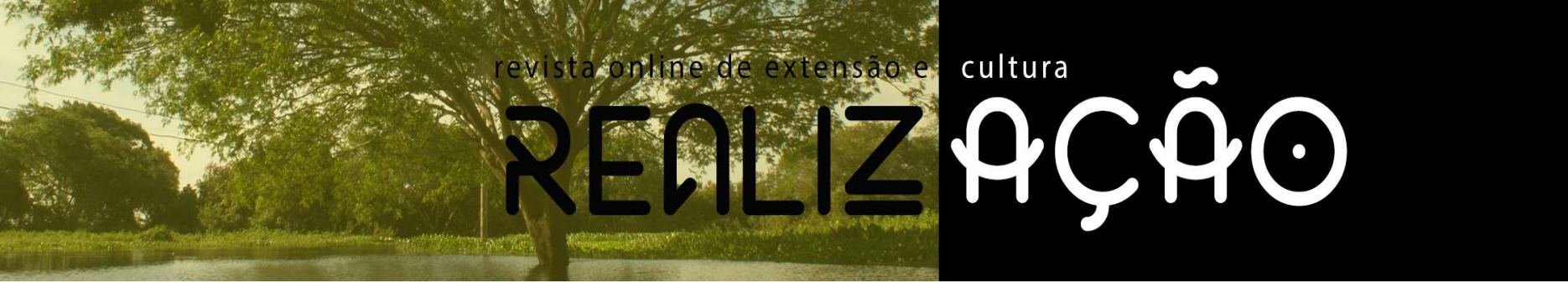

que tem que ser usada, mas não eu quero fazer assim, e aí?! Então pra mim o mais difícil da gestão é fazer com que as pessoas entendam que eles estão ali para cumprir regras, esses deveres e tem esses direitos. [sic] (ENTREVISTADOR 1).

É não, assim por exemplo, eu tenho muita satisfação por exemplo, é assim a realização é muito grande, mas eu ainda me sinto professor, então quando surge uma oportunidade deu estar em sala de aula, como essa semana é surgiu, uma professora pediu licença, só que ela ligou pra mim em cima da hora, eu tava saindo de casa e não deu tempo de eu chamar uma pessoa pra ficar no lugar dela, eu entrei em sala de aula, e esse entrar em sala de aula me faz muito bem, é assim eu, sinto muito mais vida é, me sinto muito mais motivado trabalhando com as crianças do que administrando, é, pra mim, ser gestor? Esses três anos eu não pretendo me candidatar e nem se eu for indicado eu não quero continuar na direção, é foi uma experiência legal, gratificante, mas não tão prazerosa quanto ser professor, eu ainda prefiro é administrar crianças, ensinar, porque ali você vê, é você tem um calor humano melhor, maior do que trabalhar com adultos. [sic] (ENTREVISTADO 2)

$\mathrm{O}$ ato de administrar vem carregado de direitos e deveres, assim como aquele que administra deve ter a capacidade de saber ouvir, de ver e analisar todos os acontecimentos de forma que venha proporcionar a crescimento e o respeito entre os diferentes participantes de sua gestão, relevando os pontos negativos e positivos, de forma a proporcionar o bem de toda a comunidade escolar. De acordo com Souza:

A gestão democrática é aqui compreendida, então, como um processo político no qual as pessoas que atuam na/sobre a escola identificam problemas, discutem, deliberam e planejam, encaminham, acompanham, controlam e avaliam o conjunto das ações voltadas ao desenvolvimento da própria escola na busca da solução daqueles problemas. Esse processo, sustentado no diálogo, na alteridade e no reconhecimento às especificidades técnicas das diversas funções presentes na escola, tem como base a participação efetiva de todos os segmentos da comunidade escolar, o respeito às normas coletivamente construídas para os processos de tomada de decisões e a garantia de amplo acesso às informações aos sujeitos da escola. (SOUZA, 2009, pág.125)

Entrevistador: De quanto em quanto tempo é reformulado o PPP da sua escola? E como ele é construído?

\footnotetext{
"Na nossa escola aqui é, é ficou um bom tempo. O primeiro PPP quem construiu foi eu, lá em 2000. Então é o primeiro PPP daqui foi feito em 2000, aí eu saí daqui em 2005 voltei em 2013, ele tinha parado. Na verdade o PPP tem que ser renovado todo ano, de 2013 pra cá, todo ano nós injetando as coisas que entram, por exemplo tem projetos que entram diferentes do outro ano, tem projeto que são padrão né? Que todo ano tá lá, mas têm outros que entra. Então o PPP ele tem que ser reformulado poucas coisas , por exemplo o quadro de funcionários, muda uma coisa ou outra, tem que ser
} 


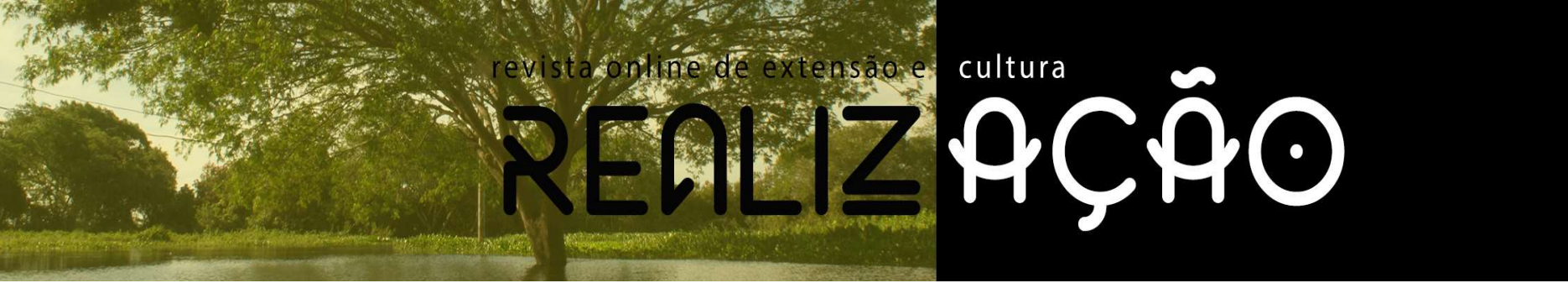

reformulado, então ele tem que ser reformulado todo ano e o nosso tá sendo reformulado desde 2013 todo ano um pouquinho" [sic] (ENTREVISTADOR 1)

A gente sempre tá aprimorando, por exemplo: ele existe, ele foi elaborado, inclusive é houve esse ano, inclusive ano passado com toda a equipe, é, mas sempre é são coisas que são acrescentadas, porque ali também cabe os projetos da escola, nós temos alguns projetos que são desenvolvidos no decorrer do ano inteiro, como o projeto que acontece no primeiro ano e no segundo ano que é o Projeto da Estrela Dourada, que não é um projeto nem de um dia nem de um mês, é de um ano inteiro mesmo, é agora essa semana a Pastora Márcia que também é uma parceira da nossa escola, ele vem toda a segunda feira abrir a semana com hino de louvor e uma oração com as crianças, é aquela aproximação é a criança e a parte espiritual que a gente sente a necessidade. Ela vai lançar um projeto Como Salvar Uma Vida, que é um projeto que envolve quase todos os tipos de assunto, bullying, racismo, droga, então a gente vai estar acompanhando este projeto semana que vem e eu já conversei com a equipe escolar que eu vou estar lançando, colocando na agenda cultural da escola, que nós temos uma agenda cultural que a gente segue pra já tá aplicando, independente se ano que vem ela não participa, não aplica de novo, a gente vai tá trabalhando, porque nós temos muitas crianças que se envolvem com droga, prostituição, com roubo e aí se a gente não trabalha esses valores, não adianta muito trabalha também a questão da aprendizagem focando os dois assuntos, até mesmo o referencial curricular a gente modifica muito porque às vezes qual a necessidade de uma criança saber quais são os planetas do sistema solar se ele ta já fumando maconha, se ele já ta usando álcool, mesmos alunos pequenos, e nós atendemos do primeiro ao quinto ano. O quinto ano mesmo esse ano criança com maconha, então que dize, a gente tenta trabalha mais aquilo que está na realidade deles, talvez uma criança lá da escola particular do quinto ano nunca tenha visto esse tipo de droga, mas as nossas não só vêem como alguns pais vendem e como algumas crianças usam então a gente fica trabalhando o tempo todo com, a gente às vezes tira algum tema do referencial e coloca outros de acordo com a nossa necessidade, de acordo com a nossa realidade. [sic] (ENTREVISTADO 2)

O PPP escolar é uma forma de estruturar todo o trabalho pedagógico de uma escola, a fim de buscar seu próprio desenvolvimento e autonomia, buscando sempre a qualidade do processo de ensino-aprendizagem, em que a partir da sua construção nota-se que a gestão está aberta a sugestões, desmistificando a idéia de uma gestão na vertical, na qual somente o gestor escolar pode ter um posicionamento da escola. Na concepção de Veiga (2005) o PPP é uma vertente em que:

Ao se constituir em processo participativo de decisões, preocupa-se em instaurar uma forma de organização do trabalho pedagógico que desvele os conflitos e as contradições, buscando eliminar as relações competitivas, corporativas e autoritárias, rompendo com a rotina do mando pessoal e racionalizado da burocracia e permitindo relações horizontais no interior da escola (VEIGA, 2005, p.38) 


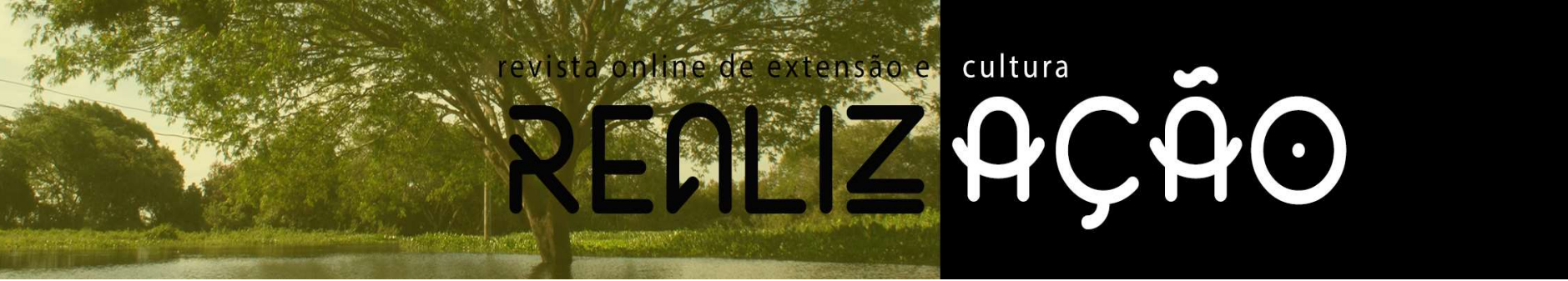

Entrevistador: O que você pensa sobre a escola de hoje, ela precisa mudar algum aspecto ou está boa do jeito que está?

"Ela precisa mudar muito, eu assisti uma reportagem esse final de semana e, fiquei muito feliz que era uma escola do meu Ceará, né? Que ta com nota oito, oito. Todo mundo fala mal do meu Nordeste né? Mas olha aí, onde tem oito? É no meu Nordeste. Então eu assisti uma reportagem dessa escola e eu fiquei assim, maravilhada, porque era essa escola que eu gostaria de ter. Se eu tivesse uma escola minha, que nem eu falei com um amigo meu empresário que eu tava conversando esses dias. Eu só sou chefe, porque eu tenho essa caneta que eu posso dispensar a hora que der problema, mas eu não queria ser você um dia, chefe de funcionário público, porque não é fácil. Eu tenho assim situações que eu quase vou lá e dou aula pro professor pra ele ver que a aula tem que ser diferente, não adianta querer culpar o pai, a mãe. Tá certo que quando a mãe participa que quando os pais tão junto com a escola é outra coisa, tudo isso ajuda. Mas o fazer pedagógico o professor tem que mudar, porque as mídias, os meios de comunicação, tão ai, tão assim, viajando e nós estamos lá na idade da pedra que nem aquele texto lá existe um texto que virou o mundo, chegou voltou à escola estava no mesmo jeito. Tudo mudou menos a escola, e nós estamos nesse padrão. Aqui eu tenho tentado do segundo ao quinto que é a área que eu sou que eu coordeno pedagogicamente, mudar um pouco essa situação, inclusive no que se refere à leitura né, projeto aqui não tinha nada quando eu cheguei aqui, o dia das mãe só tinha a mãe. O que a mãe vem fazer aqui na escola se deles filho não tão para apresentar alguma coisa, se os filhos deles não tão pra mostrar o que aprenderam. Cê entendeu? Porque tem um nível alto de desistência? Porque as aulas não são atraentes e o professor diz que é culpa do aluno, estudar é uma coisa chata então tem que ser prazerosa pra deixar de ser chata, entendeu? Então eu acho que a escola tá muito longe do que deveria ser, tem que ter qualidade e não quantidade" [sic] (ENTREVISTADO 1)

"Hoje na minha opinião a dificuldade maior pelo menos na minha escola e talvez nas escolas municipais, nas escolas públicas no geral, a ausência da família. Por exemplo: se marca uma reunião pra entrega de notas não vem o pai ou a mãe pra receber o boletim, passa o ano todo e a mãe não aparece nenhuma vez pra saber como que o filho está na escola, qual é o seu desenvolvimento, qual a sua aprendizagem, não aparece. Eu faço uso de estratégias na entrega de notas, é assim: a reunião do primeiro bimestre, entrega de camisetas, só vou entregar a camiseta na reunião, aí os pais vem, porque caso contrário, uma outra coisa eles não vem, e eu tenho pais que só aparecem no dia da matrícula, efetua a matrícula e some. E aí é complicado, se escola e família não andam junto, o resultado não é satisfatório, e escola tem como finalidade o ensinar, mas o educar cabe a família. E hoje eu acredito que a família, é uma instituição bem debilitada". [sic] (ENTREVISTADO 2)

Além das dificuldades e problemas citados pelos entrevistados, um dos pontos que chama a atenção é a dificuldade por parte de um dos gestores em ter a participação da família dentro da escola, que apesar dos projetos criados e propostos na escola, são poucos os pais que participam 


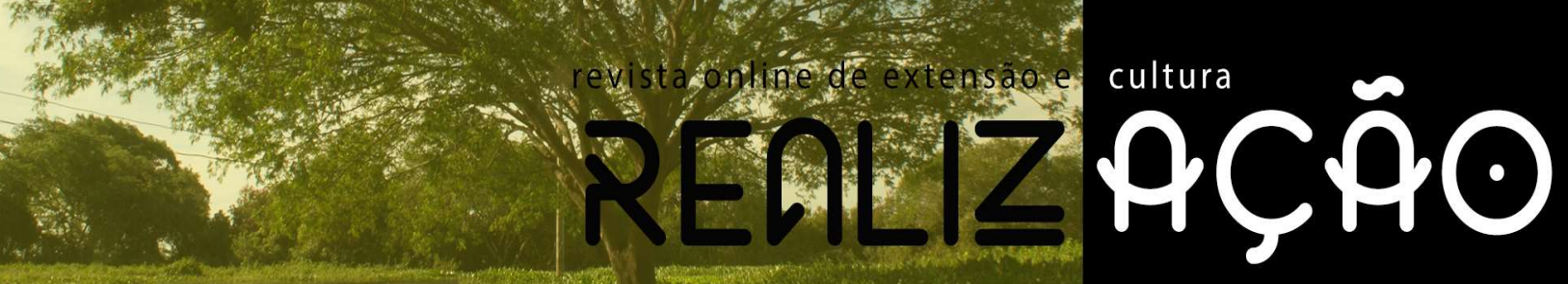

ou estão dentro da escola acompanhando a vida escolar de seus filhos. Em uma gestão democrática a presença dos pais é fundamental para o desenvolvimento da aprendizagem e para a o crescimento da escola junto à comunidade escolar. As mudanças no comportamento dos alunos depende a interação de seus pais com sua vida escolar e social, sendo que no próprio PPP da escola vem inserido sobre a importância da família na escola.

Conforme Dessem e Polonia (2007, p. 22):

A escola e a família compartilham funções sociais, políticas e educacionais, na medida em que contribuem e influenciam a formação do cidadão. Ambas são responsáveis pela transmissão e construção do conhecimento culturalmente organizado, modificando as formas de funcionamento psicológico, de acordo com as expectativas de cada ambiente. Portanto, a família e a escola emergem como duas instituições fundamentais para desencadear os processos evolutivos das pessoas, atuando como propulsoras ou inibidoras do seu crescimento físico, intelectual, emocional e social.

Ambos são necessários para a formação da cidadã, pois cada um possui a sua função, a família é o primeiro lugar de socialização da criança e tem uma função básica que é a transmissão de valores, já a escola possibilita que estes valores sejam respeitados pelos demais membros e participantes da escola, assim como tem a função de mediar conhecimento para que o aluno possa aprender

Entrevistador: Como você vê seu papel de gestor hoje na escola?

"Então é assim, tem várias situações. Eu peguei a gestão daqui, porque teve um problema que aconteceu com a diretora e eu fui pra direção tipo, toma o filho é teu, aqui tava acontecendo muitos problemas em termo de relacionamento e também de fazer pedagógico na sala de aula e aí o que eu to fazendo, to gerenciando esses conflitos né? Pra poder fazer a união. Porque eu acho que só pode fazer alguma coisa, se você conquista essa pessoa pra te ouvir. Eu tenho essa opinião comigo .... Hoje na minha gestão eu estou pisando em ovos, porque tem muitos conflitos aqui que tem que ser sanado pra poder o trabalho fluir, tenho uma dificuldade muito grande nesse meu início de gestão por conta disso. E das outras vezes todo início não é fácil, infelizmente só me dão escola que está explodindo, né? Ai eu tenho que passar um ano, seis meses sei lá quanto pra fazer as coisas acalmar pra eu poder fazer as coisas acontecer. Não adianta bater na mesa, e falar vamos fazer tal projeto, não é assim, na minha cabeça não é assim que funciona, porque quando eles não querem fazer eles não fazem. Não adianta, eles te ouvem ficam quietos entra na sala e não fazem nada é desse jeito que tá. Então minha gestão agora é essa eu to fazer, já ta dando uma amaciada e já aconteceu coisas maravilhosas" [sic] (ENTREVISTADOR 1)

O entrevistador 2 não respondeu a questão, pois disse que já discorreu sobre esta, nas respostas anteriores. 
Ao se fazer uma análise sobre as entrevistas com os diretores sobre a gestão escolar, percebemos a presença de muitas coisas que são discutidas no curso de Pedagogia, como o fato da diretora comparar a escola com uma empresa que é algo que Paro (2010) discuti, podemos destacar também Luck (2009) que chama a atenção para a questão da escola democrática e participativa, do qual ambos os diretores dizem acreditar e trabalhar de forma democrática, mas que de fato muitas vezes sentem dificuldade em lidar com a gestão. Os conselhos escolares existem, mas muitas das vezes não supre ou ajuda a resolver os problemas enfrentados pela escola, ele existem mas não funciona adequadamente.

\section{Considerações Finais}

Percebe-se que o papel do gestor é de suma importância para o funcionamento de uma escola, e é através de uma gestão democrática que a esta desenvolve sua autonomia, a fim de buscar a qualidade no ensino, e também qualidade no âmbito escolar, primando por um verdadeiro ensino de qualidade.

Outro ponto observado é que quando uma escola atua em conjunto, buscando diálogo e estimulando a participação efetiva dos integrantes de todos os segmentos da comunidade escolar, o princípio de democratização pode ser alcançado. Nota-se também, que o que o envolvimento da comunidade escolar, está diretamente ligada à escola, buscando sua autonomia e melhoria, desmistificando o processo "vertical", no qual o diretor é quem tem todo o poder dentro da escola.

Os desafios para que de fato a gestão democrática exista nas escolas, são inúmeros, pois é um trabalho árduo, uma vez que, é preciso envolver diferentes pessoas, com opiniões divergentes e administrar estas questões, exige prudência e maturidade. Por isso, o gestor escolar precisa ter um perfil para estar neste tipo de função escolar, para que seu trabalho se torne eficaz, refletindo assim, em uma escola de qualidade.

\section{REFERÊNCIAS}

BRASIL. Dados do Ideb. INEP (Instituto Nacional de Estudos e Pesquisas Educacionais Anísio Teixeira). Disponível em: portal.inep.gov.br/web/guest/ideb. Acesso em Dezembro de 2017.

CURY, Carlos Roberto Jamil. Gestão Democrática da Educação: exigências e desafios. Revista RBPAE, v.18, $\mathrm{n}^{\circ}$ 2, Jul/Dez. 2002. Disponível em: <https://scholar.google.com.br $>$ Acesso em Novembro de 2017. 


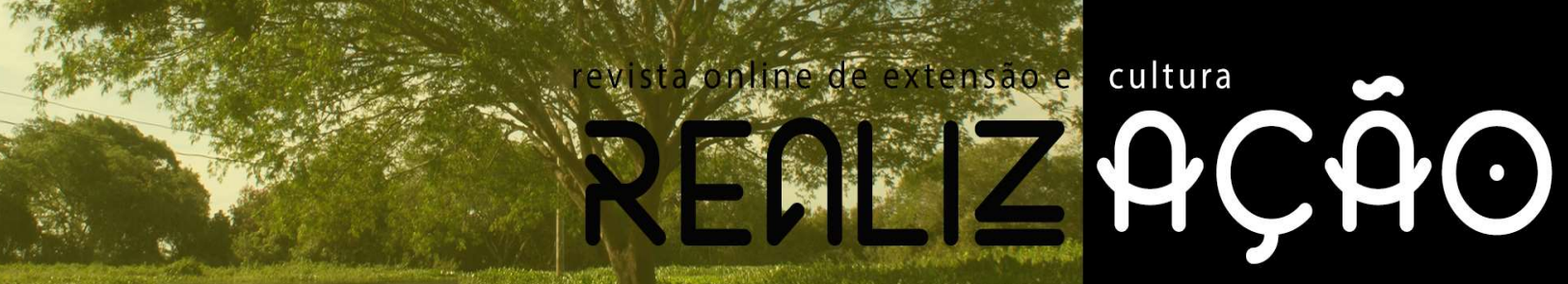

DESSEM Maria Auxiliadora; POLONIA, Ana da Costa. A Família e a Escola como contextos de desenvolvimento humano. Paideia (Ribeirão Preto), v. 17, p. 21-32, 2007.

LAKATOS, Eva Maria. FUNDAMENTOS DE METOdOLOGIA CIENTÍFICA. 5. Ed. São Paulo: Atlas, 2003.

LUCK, Heloisa. Dimensões da gestão escolar e suas competências. Ed. Positivo, Curitiba, 2009. MARCONI, Marina de Andrade; LAKATOS, Eva Maria. Fundamentos de metodologia científica. 2. Ed. São Paulo, SP: Atlas, 1990.

PARO, Victor Henrique. A educação, a política e a administração: reflexões sobre a prática do diretor de escola. Educação e Pesquisa, São Paulo, v.36, n³, pg.763 - 778, Set/Dez de 2010.

TRIVIÑOS, Augusto Nibaldo Silva. Introdução à pesquisa em ciências sociais: a pesquisa qualitativa em educação. São Paulo: Atlas, 1987.

PARO, Victor Henrique. A educação, a política e a administração: reflexões sobre a prática do diretor de escola. Educação e Pesquisa, São Paulo, v.36, n³, pg.763 - 778, Set/Dez de 2010.

VEIGA, Ilma Passos Alencastro. Projeto político-pedagógico da escola. Papirus Editora, 2005. 